\title{
ANÁLISE DO USO DA TERRA NA MICROBACIA DO ARROIO DO MEIO - SANTA MARIA - RS, POR SISTEMA DE INFORMAÇÕES GEOGRÁFICAS E IMAGEM DE SATÉLITE ${ }^{1}$
}

\author{
GEOGRAPHIC INFORMATION SYSTEM AND SATELLITE IMAGE TO ANALYSE \\ THE ARROIO DO MEIO MICROBASIN LAND USE - SANTA MARIA - RS
}

\author{
Edson Luís Piroli ${ }^{2}$ Elsbeth Léia Spode Becker ${ }^{3}$ Edson Luis Bolfe ${ }^{4}$ \\ Rudiney Soares Pereira ${ }^{5}$
}

\section{RESUMO}

\begin{abstract}
O objetivo desse trabalho foi verificar a viabilidade do uso de um Sistema de Informações Geográficas (SIG) e a imagem de satélite para a análise do uso atual da terra e localização de áreas onde possam estar ocorrendo conflitos entre capacidade e uso do solo, na microbacia hidrográfica do Arroio do Meio. Foram utilizadas técnicas de geoprocessamento, como álgebra entre mapas, consulta ao banco de dados $e$ reclassificação de imagens. Uma microbacia foi escolhida como objeto deste estudo, por ser considerada por muitos autores como sendo uma das melhores unidades para o planejamento $e$ desenvolvimento sócioeconômico dos habitantes do meio rural. Na microbacia estudada, foram encontrados 555 ha cobertos com florestas, compreendendo $24 \%$ da área total. As lavouras com área de 1.314 ha ocupam a maior parte da microbacia (56\%). Os campos de pastagens cobrem 184ha, ou seja, 8\% da área total. As áreas alagadas representam $11 \%$ da área da microbacia, tendo respectivamente $265 \mathrm{ha}$. Foram detectados ainda, $31 \mathrm{ha}$ sombreados (1\%) onde não se determinou com exatidão o uso da terra. Nas áreas com declividade superior a 47\%, foram detectados $32 \mathrm{ha}$ sem cobertura de florestas, perfazendo 1,4\% da área da microbacia. Em declives superiores a 30\%, existem 71 ha (3\%) sendo usados para a agricultura. A área ocupada com Chernossolos e Neossolos Litólicos, unidade de mapeamento Ciríaco-Charrua em declividade maior que $30 \%$ sem cobertura florestal é de 14 ha $(0,6 \%)$. De acordo com a declividade e o solo, as áreas de conflito alcançam 5\% da área total, o que demonstra que, na maior parte da microbacia, a terra está sendo usada de acordo com sua capacidade.
\end{abstract}

\begin{abstract}
Palavras-chave: sistema de informações geográficas, imagem de satélite, uso da terra.
\end{abstract}

\section{SUMMARY}

Geographic Information System (GIS) and satellite image were tested to analyze the current land use and automatic localization of areas where conflicts between present land use and land capability occurence, in Arroio do Meio watershed. Geoprocessing techniques map algebra, consultation database and image reclassification were used. The watershed object of this study was chosen because it is considered by many authors, the best unit for social and economic planning and development of population of rural areas. In the studied microbasin: $555 \mathrm{ha}$ was covered by forests (24\% of the total area). Cultivated crops occupy 1.314ha, 56\% of the microbasin. Glassland covers 184ha ( $8 \%$ of the total area). The flooded areas represent $11 \%$ of the area of the microbasin, with 265ha. The use of 31 ha could not be detected with accuracy due to shadowing. In areas with steepness above $47 \%$, 32ha were detected without forest cover, totalizing $1,4 \%$ of the area of the microbasin. With slopes above $30 \%, 71$ ha (3\%), are used for agriculture. Areas with Phaeozems and leptosols (Ciriaco-Charrua mapping units) with slopes above $30 \%$ and without forest coverage performe 14 ha $(0,6 \%)$. Areas with conflict use reached only $5 \%$ of the total area, indicating that in most of the microbasin, the land is being used in agreement with its capability.

Key words: geographic information system, satellite image, land use.

\footnotetext{
${ }^{1}$ Parte da Dissertação de Mestrado do primeiro autor, apresentada ao Programa de Pós graduação em Engenharia Agrícola, Universidade Federal de Santa Maria (UFSM).

${ }^{2}$ Engenheiro Florestal, Mestre, Aluno do Programa de Pós-graduação em Agronomia, área de concentração: Energia na Agricultura da Universidade Estadual Paulista, Campus de Botucatu. Rua Ana Maria Rodrigues, 307, Residencial Universitário, 19063-731, Presidente Prudente, SP. E-mail: piroli@agro.unoeste.br.

${ }^{3}$ Especialista em Interpretação de Imagens Orbitais, Aluno do Programa de Pós-graduação em Engenharia Agrícola da UFSM.

${ }^{4}$ Engenheiro Florestal, MSc., Pesquisador EMBRAPA Tabuleiros Costeiros, Av. Beira Mar, 3250, 49025-040, Aracajú, SE.

${ }^{5}$ Engenheiro Florestal, Doutor, Professor Titular do Departamento de Engenharia Rural da UFSM.
} 


\section{INTRODUÇÃO}

Com o lançamento em 1972, do ERTS (Earth Resources Technology Satellite) - Landsat 1, primeiro satélite colocado em órbita pela NASA (National Aeronautics and Space Administration) com o objetivo de permitir a aquisição de dados da superfície terrestre de forma global, sinóptica e repetitiva, os Estados Unidos da América deram o passo inicial para o desenvolvimento dos satélites de levantamentos ambientais da superfície do Planeta. Com o final da Guerra Fria, muitas das tecnologias empregadas para aquisição de dados de interesse militar perderam a classificação de segredo estratégico e vieram a público, favorecendo o desenvolvimento das ciências ligadas às áreas de levantamento, planejamento e monitoramento do uso de recursos naturais.

Os dados de sensoriamento remoto têm ampla aplicação na descrição quantitativa de bacias hidrográficas e redes de drenagem. Assim, uma série de estudos morfométricos, antes realizados a partir de dados extraídos de cartas topográficas, passaram a ser feitos com base em dados de sensoriamento remoto, ou seja, nas imagens coletadas por sensores remotos (NOVO, 1992). A extensão do território brasileiro e o pouco conhecimento dos recursos naturais, aliados ao custo de se obter informações por métodos convencionais, foram os fatores decisivos para o país entrar no programa de sensoriamento por satélite (ROSA, 1995).

Para o manuseio e análise dos dados provenientes de sensores remotos, os aplicativos mais usados atualmente são os de processamento digital de imagens e os denominados Sistemas de Informações Geográficas (SIGs). Estes aplicativos são capazes de armazenar, analisar e localizar espacialmente dados de um fenômeno. Além disso, permitem o manuseio e a saída de dados já analisados e tratados.

$\mathrm{O}$ primeiro sistema a reunir as características básicas de um SIG foi implementado no Canadá, em 1964, chamado de Canadian Geographic Information System (TEIXEIRA et al., 1992). Desde então, com a evolução dos equipamentos (hardware) e aplicativos (softwares) ocorreram avanços consideráveis, com o desenvolvimento de sistemas cada vez mais potentes e com muitas novas aplicações.

Os SIGs são, conforme CALIJURI \& ROHN (1994), uma excelente ferramenta para investigação de fenômenos diversos, relacionados à engenharia urbana, meio ambiente, pedologia, vegetação e bacias hidrográficas. Além disso, na área ambiental, a tomada de decisões requer um conhecimento multidisciplinar. Desta forma, o computador veio resolver grande parte dos problemas de tempo, mão-de-obra e da pouca precisão quando o volume de informações é grande (PEREIRA et al., 1995).

A opção por uma microbacia como local de estudo deve-se ao fato de ser esta uma unidade onde se tem diferentes características, desde regiões altas, onde normalmente estão localizadas as nascentes dos riachos e córregos, áreas de encostas onde as águas correm com maior velocidade, e finalmente, as áreas de baixadas onde normalmente são observadas as consequências do manejo inadequado feito nas altitudes mais elevadas.

MAY et al. (1997), ao estudarem a eficiência de imagens do mapeador Thematic Mapper (TM) para o mapeamento de arbustos e campinas na Califórnia (EUA), conseguiram bons resultados para a separação de arbustos de campinas; no entanto, não conseguiram eficiência para separação de tipos de campinas. ALVES et al. (1998) comentam que o uso de imagens de satélite tem possibilitado o estudo do desflorestamento em várias regiões do Planeta, particularmente em regiões tropicais, onde extensões significativas de florestas não poderiam ser monitoradas facilmente sem o recurso dos satélites de sensoriamento remoto. VALÉRIO FILHO et al. (1997), ao utilizarem dados digitais do TM/Landsat e geoprocessamento para o monitoramento da dinâmica do uso agrícola e vegetação natural em microbacias, concluíram que, mesmo não sendo possível um maior detalhamento das classes de uso e cobertura vegetal das terras, face às limitações dos produtos de sensoriamento remoto ao nível orbital, as técnicas de sensoriamento remoto $\mathrm{e}$ geoprocessamento são ferramentas úteis para o monitoramento da dinâmica de uso e cobertura vegetal e a adequação de uso das terras ao nível de microbacias hidrográficas, pelo fato de propiciar maior frequência na atualização de dados, agilidade no processamento e ser economicamente viável.

O objetivo deste trabalho foi analisar a aplicabilidade de um SIG e de imagem do satélite Landsat 5 - TM (Thematic Mapper) para determinação do uso atual da terra, cruzamento entre mapas temáticos e localização de áreas propícias à ocorrência de devastação florestal e erosão na microbacia hidrográfica do Arroio do Meio, através da determinação de índices morfométricos e da análise de suas principais características físicas.

\section{MATERIAL E MÉTODOS}

Neste trabalho, analisou-se a área ocupada pela microbacia hidrográfica do Arroio do Meio, no município de Santa Maria, RS. Este Arroio situa-se em uma região povoada e bastante explorada com 
relação aos seus recursos naturais, como o solo, a vegetação e a água. Por ser um dos afluentes do Rio Vacacaí-mirim, o Arroio do Meio é um tributário do Rio Jacuí. O Rio Jacuí, por sua vez, é formador da bacia hidrográfica que drena toda a porção leste do Estado do Rio Grande do Sul e é um dos principais responsáveis pela formação do estuário do Rio Guaíba.

Os materiais empregados para a realização deste trabalho foram uma imagem digital TM (Thematic Mapper) do satélite Landsat 5, órbitaponto 223/081 quadrante $\mathrm{B}$, de 27 de outubro de 1994, adquirida junto ao Instituto Nacional de Pesquisas Espaciais (INPE) cartas topográficas, mapa de solos, equipamentos e aplicativos.

As cartas topográficas, usadas para georreferência da imagem de satélite e como fonte de dados para digitalização dos elementos de drenagem e curvas de nível, foram em escala 1:50.000 e 1:25.000, no sistema de projeção UTM, correspondendo à folha SH.22-V-C-IV/2 - Camobi e SH.22-V-C-IV/2-SO - Camobi-SO.

O mapa de solos utilizado foi do Levantamento de Reconhecimento dos Solos do Estado do Rio Grande do Sul, efetuado pelo Ministério da Agricultura em 1973, na escala 1:750.000, por ser o único disponível no momento da realização do trabalho.

Usou-se, para o desenvolvimento das atividades, um microcomputador Pentium II com $300 \mathrm{MHz}, 64$ Mbytes de memória RAM, drive de 3 $1 / 2$ e unidade de CD-ROM. Utilizou-se ainda, scanner modelo Scanjet II CX e mesa digitalizadora Summagraphics formato A0. Além destes, também foi usado para a coleta e confirmação das coordenadas dos pontos de controle a campo, um GPS de navegação Garmin XL 45 GPS II. Os aplicativos utilizados foram o IDRISI for Windows, versão 2.0 para as análises geográficas, SITER 2.0 para georreferência e digitalização das curvas de nível, rede de drenagem e pontos de controle, ADOBE PHOTOSHOP versão 4.0 para ajustes de brilho e contraste na imagem do satélite e WORD for Windows 97 para edição de arquivos vetoriais em formato ascii.

A conversão do formato .DAT para o formato .TIF foi feita utilizando-se o programa L2TIF, distribuído pelo INPE junto com a imagem. No módulo import do IDRISI, efetuou-se a importação da imagem de formato .TIF para o formato .IMG. Pelo módulo Window, cortou-se uma janela da imagem, abrangendo-se a região da microbacia com a finalidade de diminuir o tamanho do arquivo e facilitar as análises posteriores. Após, efetuou-se a aplicação de um contraste de 2,5\% para melhorar a visualização e facilitar a identificação visual dos padrões de uso da terra.

A partir da combinação das bandas 3, 4 e 5, foi elaborada a composição falsa cor da imagem da microbacia. Composições em falsa cor são imagens coloridas produzidas a partir de três imagens independentes em preto e branco. São chamadas de composições em falsa cor sempre que contêm informação espectral fora do intervalo sensível ao olho humano. É feita associando-se 3 bandas de imagem, cada uma a uma das três cores básicas: vermelho, verde e azul, ou seja, o espaço RGB (Red, Green, Blue) de cores. Em seguida, passou-se à etapa da georreferência da imagem, com base na composição falsa cor e na carta topográfica de Camobi, em escala 1:50.000.

Após, efetuou-se a classificação digital do uso da terra, visando obter a localização das principais classes de cobertura do solo na microbacia. Elaborou-se ainda, o Modelo Digital do Terreno (MDT) com o objetivo de determinar a distribuição, a localização e a área ocupada pelas classes de declive na microbacia. Com as classes de declividade determinadas, passou-se à reclassificação das mesmas, e se transformou-as em imagens booleanas (imagens com valores 0 e 1 somente). Também foram transformadas em booleanas as imagens do uso da terra e o mapa de solos. Finalmente, efetuou-se os cruzamentos entre os mapas das classes de declive, uso da terra e de solos, com a finalidade de encontrar as áreas onde estão ocorrendo conflitos de capacidade e uso da terra.

\section{RESULTADOS E DISCUSSÃO}

Utilizando a composição falsa cor georreferenciada, efetuou-se a classificação digital do uso da terra. Nesta classificação, foram determinadas seis classes de uso representadas por coberturas agrícolas, florestais e água, perfazendo um total de 2.318ha. Além destas, foi ainda classificada uma sétima classe representando as sombras. Estas sombras ocorrem devido ao fato de o relevo da região ser bastante montanhoso, com alguns pontos muito íngremes. Nesta classe, foram classificados 31ha, cobrindo uma pequena percentagem de $1 \%$ do total da área da microbacia.

$\mathrm{Na}$ categoria floresta, foi determinada uma cobertura de 555ha, ou seja, 24\% da área total da microbacia. Nesta categoria, estão abrangidos todos os tipos de vegetação arbórea ocorrentes na microbacia, quais sejam, florestas nativas primárias e secundárias, capoeiras e capoeirões e florestas implantadas, como, por exemplo, pequenos 
povoamentos de Eucaliptus sp. usados para a produção de lenha e para a secagem do fumo que é uma das principais atividades agrícolas da região. As lavouras irrigadas perfazem $22 \%$, o que representa uma área de 527ha. Esta classe é toda ocupada com cultivos de arroz.

$\mathrm{Na}$ classe de lavouras não irrigadas, estão as áreas de várzea onde não é cultivado o arroz, porém aparecem outras culturas como fumo, milho e soja. Por serem áreas de várzea, provavelmente, estas várzeas, em anos alternados, também são utilizadas para o cultivo de arroz, o que promove a rotatividade da terra. Esta classe, de lavouras não irrigadas, cobre $152 \mathrm{ha}$, ou seja, $7 \%$ da área de estudo.

A classe de lavouras de sequeiro está distribuída em terrenos mais elevados, já com alguma declividade e em pontos isolados, em locais bastante íngremes. Esta classe é ocupada com lavouras de milho, fumo, soja, feijão e batatas. Soma um total de 635 ha, o que corresponde a $27 \%$ da área da microbacia.

A categoria de campo refere-se às áreas ocupadas com pastagens, sobretudo nativas. Nestas áreas é praticada a pecuária extensiva caracterizada predominantemente pela presença de pequenos rebanhos de bovinos. São os chamados "potreiros", onde são criadas vacas leiteiras, animais para tração e alguns para corte. Esta classe abrange uma área de 184ha, correspondendo a $8 \%$ da área total.
A água apresenta-se como um importante componente da paisagem da microbacia. Ocupa uma área de 265ha, o que corresponde a $11 \%$ da cobertura total da microbacia. Este fato deve-se a presença de grandes barragens, construídas para a irrigação da cultura do arroz. Estas barragens estão localizadas sobretudo ao Sul da microbacia, em áreas de várzea, onde captam águas de alguns córregos e recebem águas pluviais que descem as montanhas. A grande área coberta com água, ao Sul da microbacia, apesar de parecer um lago na imagem, é um conjunto de açudes localizados muito próximos entre si, com o objetivo de armazenar água para irrigar a grande área de lavoura de arroz localizada nas proximidades.

De acordo com trabalho realizado por CASSOL (1996), o limite máximo para o corte raso de florestas varia de 30 a $47 \%$ dependendo de um conjunto de fatores, tais como tipo de solo e vegetação. A partir deste limite (que é igual a $25^{\circ}$ ), a exploração só será permitida, se sustentada por planos de manejo (Lei $\mathrm{n}^{\circ} 4771 / 65$ de 15/09/65). Tomando-se estes limites como parâmetros e levando em conta os mapas do uso da terra (Figura 1), dos solos (Figura 2) e da declividade (Figura 3), passou-se à fase de análise dos dados, para localizar áreas de conflito entre uso atual e uso adequado das terras da microbacia.

Nesta etapa, foram analisados todos os locais com declividades superiores a $47 \%$, encontrando-se uma área de 32 ha desprotegidos por

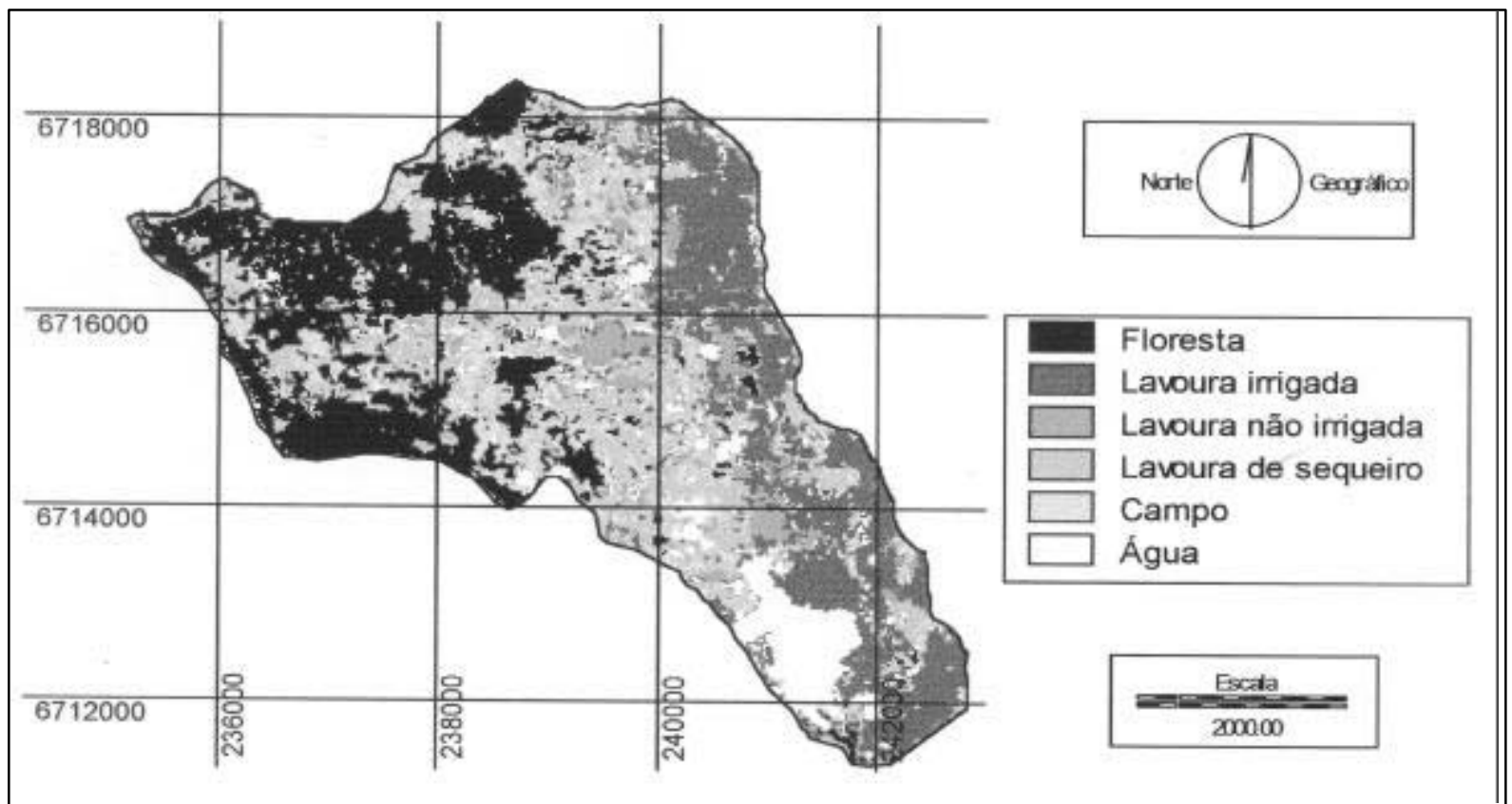

Figura 1 - Classificação digital, qualificação do uso da terra e rede de drenagem na Microbacia Hidrográfica do Arroio do Meio, Sanata Maria - RS em outubro de 1994.

Ciência Rural, v. 32, n. 3, 2002. 


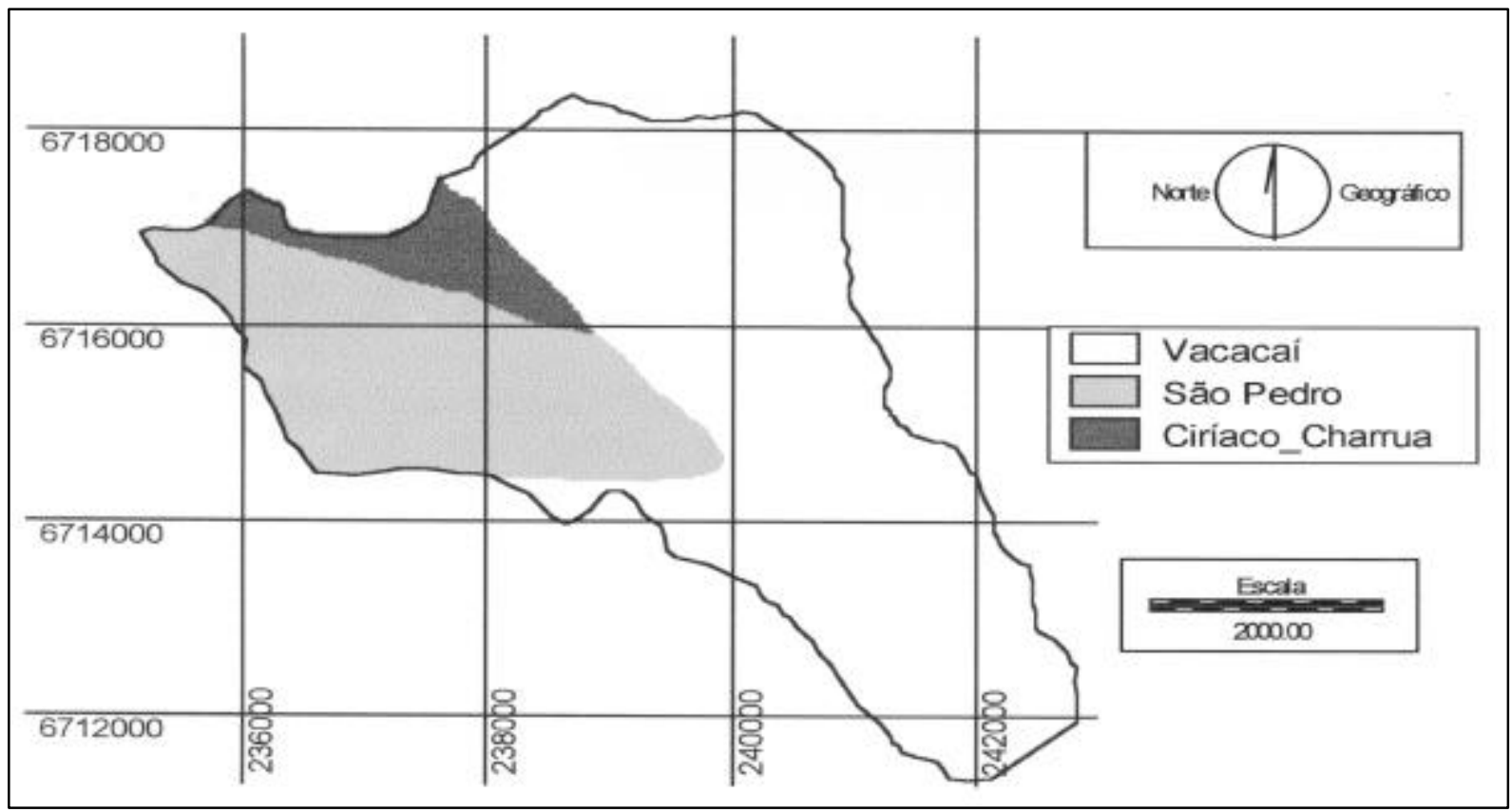

Figura 2 - Unidades de mapeamento dos solos ocorrentes na Microbacia Hidrográfica do Arroio do Meio, Santa Maria - RS em outubro de 1994.

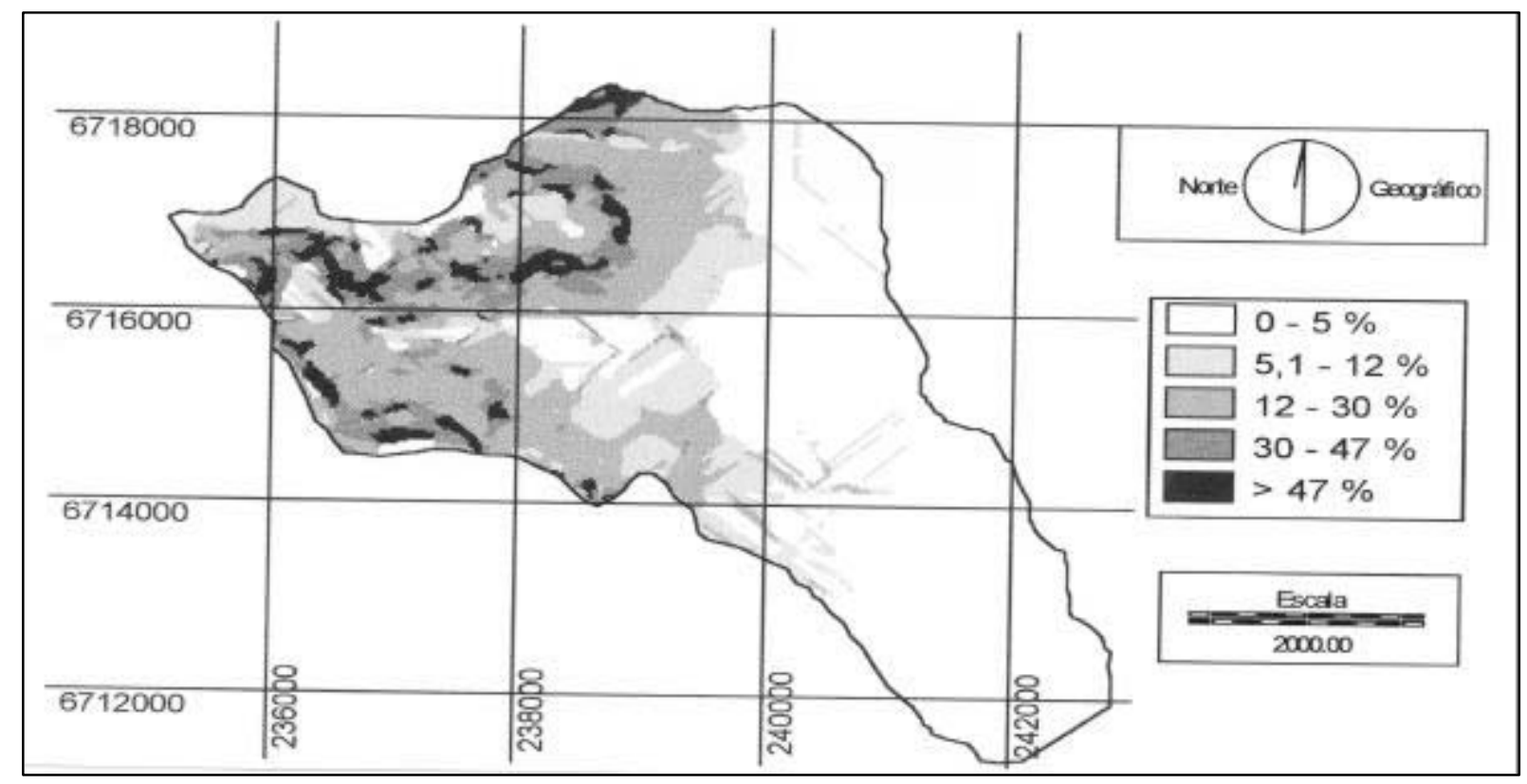

Figura 3 - Classes de declividade na Microbacia Hidrográfica do Arroio do Meio, Santa Maria - RS em outubro de 1994.

florestas, o que perfaz um percentual de 1,4\% da área total da microbacia. Estas áreas estão, em sua maior parte, localizadas nas montanhas da Serra Geral, em altitudes que alcançam $469 \mathrm{~m}$, a noroeste da microbacia.

Nas áreas com declives entre 30 e $47 \%$, foram encontrados $72 \mathrm{ha}$ sem a cobertura de florestas, o que representa $3 \%$ da área da microbacia. Em geral, estes locais são usados para a prática agrícola, porém, esta prática em áreas com esta declividade é desaconselhável, devido ao risco que representa. Além destes intervalos de declive, foram analisadas ainda, as áreas ocupadas pela associação de solos Chernossolos e litólicos, das unidades de mapeamento Ciríaco-Charrua que, 


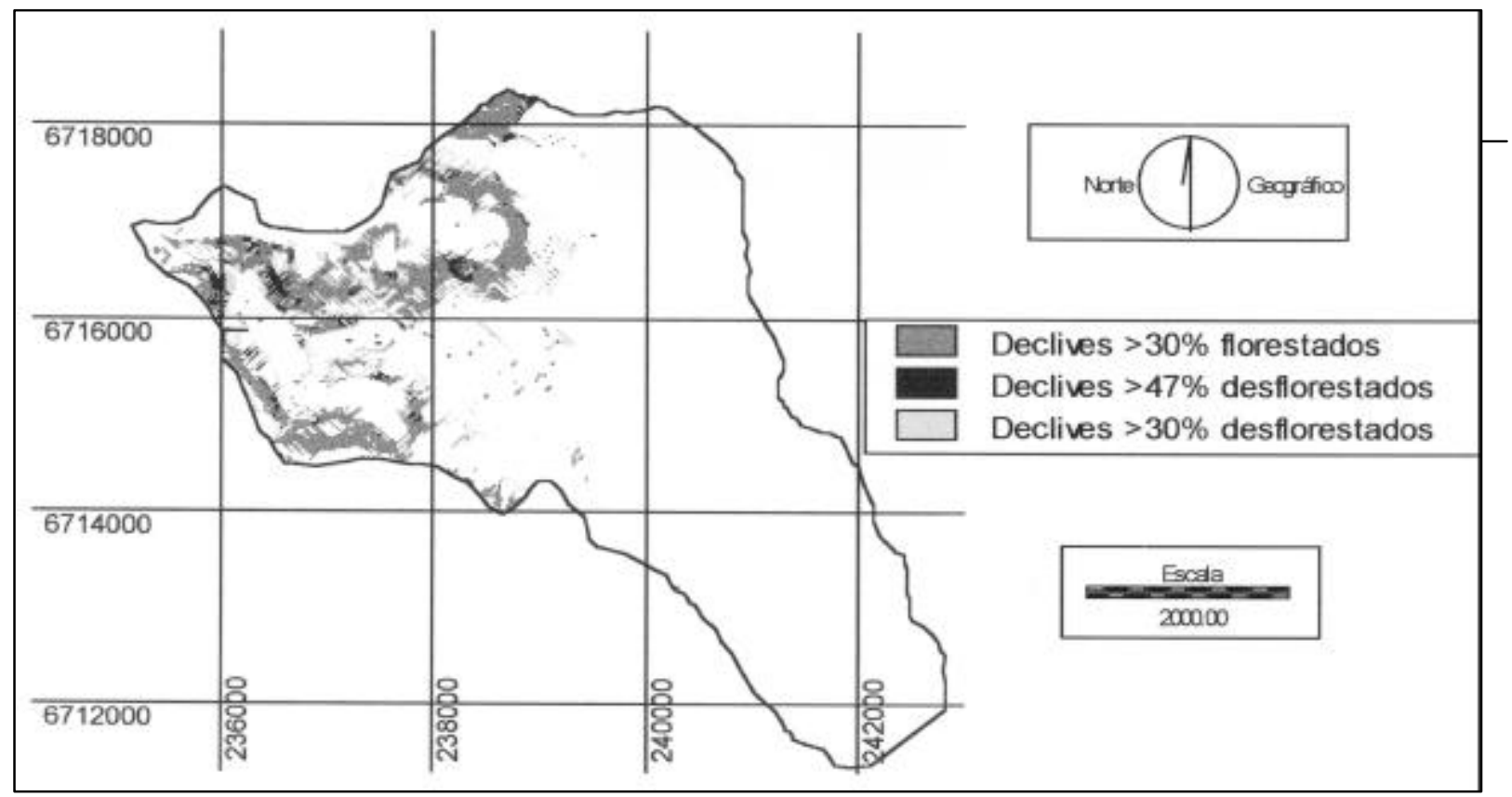

Figura 4 - Áreas com declives superiores a 30\% florestadas e desflorestadas e superiores a47\% desflorestadas (áreas de risco) na Microbacia Hidrográfica do Arroio do Meio, Santa Maria - RS em outubro de 1994.

devido às suas características, apresenta susceptibilidade à erosão de moderada a forte, o que recomenda a manutenção de vegetação perene em declividades acima de $30 \%$. Os demais solos não foram analisados devido as suas características que, em condições normais, permitem seu uso com as culturas tradicionais da região. Ao analisar-se estas áreas, verificou-se que a área coberta com florestas é de 34ha, enquanto a área com esta declividade que não apresenta cobertura florestal é de 14ha, ou seja, $0,6 \%$ da microbacia.

$\mathrm{Na}$ figura 4, é mostrada a distribuição dos locais com altas declividades (acima de 30\%), com e sem a proteção de cobertura florestal.

Verificando-se o conjunto das análises, pode-se observar que seria de $5 \%$ da área da microbacia estão sendo usados de forma inadequada. Estas áreas, ou correm risco de se deteriorarem ou já estão em processo de degradação, sofrendo com a erosão e a perda de nutrientes do solo. Nas regiões mais baixas, os moradores também começam a sentir os efeitos da degradação do solo, sofrendo com a ocorrência de enchentes e secas em intervalos de tempo cada vez menores. É necessário portanto, que se tomem medidas no sentido de diminuir estes processos e se possível, iniciae-se uma fase de recuperação ambiental com a conscientização dos produtores e da população em geral sobre o risco de estes problemas se agravarem num futuro próximo.

\section{CONCLUSÕES}

Nas condições em que foi realizado o presente trabalho e de acordo com os resultados obtidos conclui-se que:

- o Sistema de Informações Geográficas, através dos seus diferentes módulos, permite a elaboração das diversas análises necessárias ao conhecimento da ocupação atual das terras na microbacia;

- a imagem do sensor Thematic Mapper do satélite Landsat 5 fornece uma boa base de dados que, apesar de sua pouca resolução, atende às necessidades exigidas para trabalhos desta natureza, devido à rapidez com que os dados podem ser analisados e a amplitude do espaço físico alcançado;

- existem no momento da realização deste trabalho, aproximadamente 117 ha $(5 \%$ da área total da microbacia) sendo utilizados de maneira inadequada, ou seja, áreas em declividades ou solos que deveriam estar protegidas com culturas perenes que estão sendo usadas para agricultura, o que pode agravar a situação do ambiente na microbacia hidrográfica do Arroio do Meio. 


\section{REFERÊNCIAS BIBLIOGRÁFICAS}

ALVES, D.S.; PEREIRA, J.L.G.; SOUZA, C.L.de, et al. Análise comparativa de técnicas de classificação de imagens do sensor Landsat/TM para caracterização de áreas desflorestadas. In: SIMPÓSIO BRASILEIRO DE SENSORIAMENTO REMOTO, 9, 1998, Santos, SP. Anais... Santos : INPE, 1998. Publicado em CD-ROM.

BRASIL, Instituto Brasileiro do Meio Ambiente e dos Recursos Naturais Renováveis. Código Florestal. Brasília, 1965. 18p.

BRASIL. Ministério da Agricultura. Levantamento de reconhecimento dos solos do Estado do Rio Grande do Sul. Recife : Divisão de Pesquisa Pedológica, 1973. 423p.

CALIJURI, M.L.; RÖHM, S.A. Sistemas de informações geográficas. Viçosa : CCET/DEC - Universidade Federal de Viçosa, Imprensa Universitária, 1994. 34p.

CASSOL, R. Zoneamento ambiental elaborado com variáveis otimizadas estatis-ticamente, geradas por técnicas cartográficas. São Paulo, 1996. 292p. Tese (Doutorado em Geografia) - Universidade de São Paulo, 1996.

MAY, A.M.B; PINDER, J.E.; KROH, G.C. A comparision of Landsat Thematic Mapper and SPOT multi-spectral imagery for the classification of shrub and meadow vegetation in northern California, U.S.A. International Journal of Remote Sensing, v.18, n.18, p.3719-28., 1997.

NOVO, E.M.L. Sensoriamento remoto, princípios e aplicações. São Paulo : Blucher, 1992. 308p.

PEREIRA, R.S.; MADRUGA, P.R. de A.; HASENACK, H. Geoprocessamento aplicado ao planejamento de uso de recursos naturais - Curso. Santa Maria : UFSM-CCRFATEC, 1995. 40p.

ROSA, R. Introdução ao sensoriamento remoto. Uberlândia : Edufu, 1995. 117p.

TEIXEIRA, A.L.de A.; MORETI, E.; CHRISTOFOLETTI, A. Introdução aos sistemas de informação geográfica. Rio Claro : ed. do Autor, 1992. 80p.

VALÉRIO FILHO, M.; DONZELI, P.L.; PINTO, S. dos A. F., et al. Monitoramento da dinâmica do uso agrícola e vegetação natural em microbacias hidrográficas através de técnicas de sensoriamento remoto e geoprocessamento. In: CONGRESSO BRASILEIRO DE CIÊNCIA DO SOLO, 26, 1997, Rio de Janeiro, RJ. Anais... Rio de Janeiro : SBCS, 1997. Publicado em CD ROM. 